\title{
Molecular Breeding in Maize Improvement
}

\author{
Sandeep Bagri, Rajat, Sahil, Harmeet Singh Janeja* \\ Department of Genetics and Plant Breeding, School of Agriculture, Lovely Professional \\ University, Phagwara (Punjab), India \\ *Corresponding author
}

\begin{abstract}
A B S T R A C T
From the initial stages of maize improvement, several techniques are being used and developed to overcome the challenge of nutritional food supply. The discoveries from the era of Darwin and Mendel genetics for the evolutionary changes in the crops have guided the development of molecular breeding. Molecular breeding deals with the manipulation of genes, employing different techniques like Quantitative trait loci (QTL) mapping, marker assisted selections, genetic transformations, etc. The foundation of molecular breeding has revolutionized the crop improvement by providing a better understanding about the genetic makeup of desired traits, thereby supplementing the conventional methods to a greater extent. Use of molecular markers, genomic selection (GS), gene discovery and genetic transformations have now become a topic of keen interest for the plant breeders and the crop scientists. The development of varieties with the help of marker-assisted selection (MAS) along with the conventional methods of plant breeding makes us capable to promote the desired gene pool of the cultivars and enhances their agronomic, nutritional and genotypic characters. These genomic selection leads to rapid and lower cost gains in breeding. Genetic transformation is another approach of molecular breeding to transfer desired genes in plants for making them resistant to biotic and abiotic stress, hence increasing the overall crop advancement. Molecular approach of breeding is holding greater importance for the developing countries after accounting successful results in developed ones with similar procedure in its application and use. Some QPM hybrids and resistant cultivars of maize like CM-137, CM-138, CM-139, CM-140, etc.are derived by the use of specific molecular markers, genomic selection of parents and recombination, however, these improved cultivars accounts very less in number.
\end{abstract}

\section{Introduction}

Maize (Zea mays L., 2n=20) domains a unique rank in agriculture owing to its varied uses viz., human consumption, poultry feed, green fodder, value added products and industrial usage. It ranks third in staple crops after wheat and rice. These three crops together provides nearly $30 \%$ of the food calories to billions of people worldwide.Its role in human consumption is expressed in terms of calorie share and varies significantly across countries (Shiferaw et al., 2011). Maize possesses the highest genetic potential for production among the cereals with a welldefined genomic system. In India, it covers 
9.34 million hectares (ha) area contributing to 25 million tonnes of production with a productivity of 2.6 tonnes/ha. A typical maize kernel contains starch $(73 \%)$, protein $(9 \%)$ and oil (4\%) (Prasanna et al., 2001). Its oil has a higher Poly Unsaturated Fatty Acids (PUFA) accounting for high nutritional quality. Although the developed nations contribute predominantly to the maize production, still the demand for this is expected to increase in developing nations in coming years (Pingali and Pandey, 2001).

The seven parts of Asian belt i.e., China, India, Indonesia, Nepal, Philippines, Thailand and Vietnam are major producing countries of maize and have shown progress in becoming the net exporters of maize from previously the importing one in the last decade (Gerpacio and Pingali, 2007). Consequently, the demand is expected to increase with the change in diet and other uses in the middle-east countries over the next decades.

Cconventional maize breeding methods like population improvement schemes, inbred development, hybridization and backcross selection has not only directed to improve the quantitative and qualitative characters but also assisted to handle the significant constraints in maize production. Despite the huge advancement in maize breeding till datewith an interestto enhance productivity, agronomic fitness, and adjustment to environmental change now becomes so difficult to continue the agricultural development, improvement in nutritional quality, and also to make sure about harvests.

Molecular breeding techniques like Quantitative trait loci (QTL) mapping, Marker assisted breeding and Genomic selection (GS) speed up this process of crop improvement (Ribaut et al., 2010). Marker assisted breeding further includes Marker assisted Selection (MAS), Marker assisted backcrossing (MABC) i.e., selection and transfer of alleles in between different genetic backgrounds and Marker assisted recurrent selection (MARS)(Bernardo and Yu, 2007).

In this review, we discuss the application of molecular breeding approaches to improve maize cultivars and considers the path line to integrate the new genomic tools with the basic breeding techniques to combat various challenges that will potentially accelerate genetic gain.

\section{Molecular breeding approaches}

\section{Quantitative trait loci (QTL) Mapping}

Quantitative trait loci (QTL) mapping is a significant way to deal with the hereditary design underlying heterosis in genes of interest, which distinguishes molecular markers statistically and very significantly associated with heterotic changes in segregating populations (Li et al., 2007; Lu et al., 2010).

Recently, the power of QTL mapping has been improved by utilizing high-density linkage maps and new measurement techniques (Li et al., 2007; Liu et al., 2016b). For instance, an important QTL'qTBN5' for the maize tassel branch number was mapped on chromosome 5.05 in a little physical interim $\sim 800 \mathrm{~kb}$ dependent on a linkage map including 6,533 bin markers(Chen et al., 2014).

\section{MAS (Marker Assisted Selection)}

MAS (Marker Assisted Selection) include identification of the desirable genes with the use of linked markers for the selection of genotypes. With specific markers, it permits finding of the ideal plant phenotype by analyzing the marker linked DNA banding pattern on a gel or autoradiogram. The pattern 
of DNA banding reveals the pedigree of segregants in bands and configures the availability of desired chromosome segment (Jhansi et al., 2014).

MAS is holding significant importance as it helps to enhance the proficiency of maize breeding by inspecting the desirable genes in breeding populations. This can be achieved by transfer and recovery of desired ones and the parental alleles i.e., foreground selection and background selection respectively. This is widely utilized for traits which are governed by single gene i.e., monogenic traits than for traits which are governed by numerous genes comprising small cumulative effects i.e., the polygenic traits.

\section{Marker assisted backcross breeding (MABB)}

MABB (Marker assisted backcross breeding) is the least complex type molecular approach of breeding, wherein the objective is consolidating a significant gene from adisease resistant plant (the donor parent) into a susceptible best performing cultivar or breeding line (the recurrent parent).Most of the time the recurrent parent used for backcrossing has almost all the desirable genes, lacking only few characters/traits (Allard, 1999).

DNA markers in backcross breeding i.e., marker-assisted backcrossing (MAB) can be utilized (Holland, 2004) at three levels-

'Foreground selection' includes markers linked with the target genes and substitute screening for the target gene or QTL is done (Hospital and Charcosset, 1997).

'Recombinant selection' includes selection of progenies with target genes after back crossing and events of recombination between the target genes and markers linked to the genes. It decreases the introgression size and 'linkage drag' (Hospital, 2005).

Background selection' includes selection of backcross progenies having the best extent of recurrent parent genome with the help of the markers not linked with the target loci (Hospital and Charcosset, 1997; Frisch et al., 1999).

Marker Assisted Backcross Breeding (MABB) permits the selection of desired genotypes at the seedling stage under any environment and effective selection of heterozygous individuals using codominant makers like SSR, SNP.

\section{Marker Assisted Recurrent Selection (MARS)}

MARS scheme-allows the selection of multiple genomic regions (within the chromosomes) expressing complex traits using markers in order to identify the bestperforming genotypes within a population (Ribaut et al., 2010). MARS permits genotypic selection followed by crossing the selected individuals in one selection cycle (Jiang et al., 2007a). Thus MARS can upgrade the proficiency of recurrent selection and accelerates the advancement in the selection process especially assisting to coordinatemultiple favourable genes or loci from various sources (Asima Gazal et al., 2015).

Forward breeding and Pyramiding multiple QTLs of desired genes have been proposed in MARS for traits such as yield, resistance to stress, etc. (Eathington, 2005; Crosbie et al., 2006). Gene mapping is required in MARS to integrate multiple QTLs expressing for the complex traits and are subjected to develop lines with genes of interest following controlled pollination. 
Fig.1 General scheme of maize cultivar development
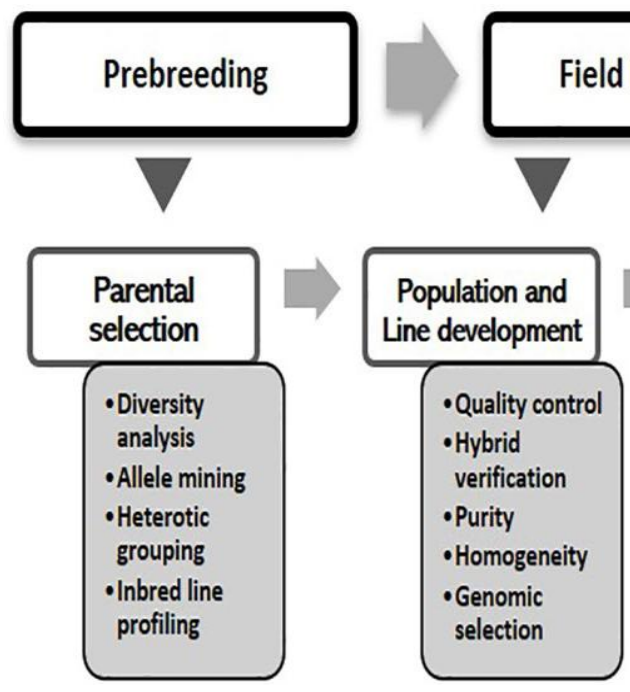

\section{Genomic selection (GS)}

Meuwissen (2007) defined genomic selection as synchronous use of markers (10 or 100 or 1000) covering complete dense genome expected to be involved in linkage. To predict the genotypic information of complex traits, genetic markers are used in particular OR to particularly predict the genotypic information of complex traits, genetic makers are used. Desired individuals are selected on the basis of genomic estimated breeding value (GEBV) (Nakaya and Isobe, 2012), calculated by using strategy dependent on genome-wide dense DNA markers (Meuwissen et al., 2001).

\section{Application of molecular markers in maize breeding}

International Maize and Wheat Improvement Center (CIMMYT) successfully coordinated the Asian Maize Biotechnology Network (AMBIONET) with the funds provided by the Asian Development Bank (ADB) from 1998 to 2005 in six countries of the Asian belt i.e., China, India, Indonesia, Philippines, Thailand and Vietnam focusing on application of molecular markers in crop improvement program by public sector foundations (Pray
AMBIONET worked collaboratively on:-

DNA fingerprinting

Analysing the genomic diversification in inbred lines

Allocating heterotic matches to inbred lines Analysing genes/QTLs resistant to biotic and abiotic stresses and
Implementation of marker assisted approaches in maize breeding program.

\section{Molecular breeding for resilience in maize}

Different biotic and abiotic stresses have negative consequences on maize yield (Gerpacio and Pingali, 2007). The molecular breeding approach includes identification of quantitative trait loci (QTLs) and associated markers, introgression in elite lines through marker-assisted backcrossing (MABC). Linkage mapping (Varshney et al., 2007) and association mapping (Gupta et al., 2005) are used to identify the QTLs associated with biotic and abiotic stresses in maize. Association mapping is likely to be favoured over linkage mapping in future in terms of 
precise resolution with less expensive approach.

Small and several epistatic QTLs effect are the difficulties in developing superior genotypes for resilience (Messmer et al., 2009). Although, integration of QTLs with MABC has been constrained as a result of the large population size for backcross. To overcome this, marker assisted recurrent selection (MARS) and genomic selection (GS) are used in one genetic background (Varshney et al., 2007).

\section{Breeding achievements}

\section{Drought tolerance}

MABC was used to incorporate several QTL alleles from Ac7643, a drought tolerant line to CML-247 maize cultivar for shortening the time interval of ASP (Anthesis-Silking period) in elite maize cultivar (Ribaut and Ragot, 2007).

\section{Downy mildew resistance}

QTLs were mapped on $6^{\text {th }}$ chromosome RIL set by crossing the resistant line $\mathrm{Ki} 3$ with the susceptible CML-139 maize cultivar (George et al., 2003).

In India, QTLs were mapped each on $3^{\text {rd }}$ and $6^{\text {th }}$ chromosome and validated from backcross mapping population obtained by making cross between the resistant NAI-116 cultivar with susceptible CM139 maize cultivar (Nair et al., 2005) and by using MABC, a resistant line (CM-139) to downy mildew was developed (Prasanna, 2009a).

Polysora Rust (PR) and Turcicum leaf blight (TLF) resistance

$C M-137, C M-138, C M-139, \quad C M-140$ and $C M-212$ lines of maize were validated as PR and TLF resistant by use of MAS at IARI, India (Prasanna et al., 2010a;Prasanna et al., 2009b).

NAI-147, SKV-21, NAI-112 and SKV-18lines of maize were validated for TLF resistant genes (Htnland Ht2) along with mapping QTL 'RppQ' for PR resistance in 7 backcross populations.

\section{Banded leaf and sheath blight (BLSB) resistance}

Causal organism - Rhizoctonia solani Kuhn

In India, $2^{\text {nd }}$ and $3^{\text {rd }}$ segregating populations were mapped to obtain the BLSB- resistant line by using tolerant line i.e., CA00106 and susceptible line i.e., CM-140 in maize (Garg et al., 2009).

\section{Success in advanced molecular breeding}

Development of quality protein maize (QPM) with enhanced nutritional value is achieved by utilization of opaque2-specific SSR markers (Prasanna et al., 2001; Morris et al., 2003; Babu et al., 2005).

'Vivek QPM Hybrid 9' is another example, developed by transferring marker linked opaque2 gene into the parental lines i.e., CM145 and CM-212 and phenotypic screening for the endosperm mmodifiers in Vivek Hybrid 9 (Babu et al., 2005; Gupta et al., 2009) recently released by VPKAS, Almora, India.

In conclusion the application of molecular breeding for maize improvement has significantly increased in recent years and has helped in enhancing the systematic understanding of germplasm, identification of QTLs/genes by high resolution mapping and the introgression of desired alleles in cultivars/varieties/genotypes. Molecular breeding provides an opportunity for plant 
breeders to precisely develop superior genotypes with resilience to biotic and abiotic stress in a less time duration as discussed above. Cost and availability of genomic tools are the bottle necks which hinder molecular breeding strategies especially in developing nations. To counter these challenges platforms need to be developed to access genomic tools with public and private support services across the globe .It is important to focus on the constraints in maize improvement and wise use of genomic tools to develop superior cultivars.

\section{References}

Allard, R.W., 1999. Principles of plant breeding, 2nd edn. New York, NY: Wiley.

Asima Gazal, Z.A., Dar, A.A., Lone, I. and Abidi, A.G. 2015. Molecular breeding for resilience in maize. Journal of Applied and Natural Science. 7(2):10571063.

Babu, R., Nair, S.K., and Kumar, A. 2005. Two-generation marker-aided backcrossing for rapid conversion of normal maize lines to quality protein maize (QPM). Theor Appl Genet. 111:888-897.

Bernardo, R., and Charcosset, A. 2006. Usefulness of gene information in marker-assisted recurrent selection: A simulation appraisal. Crop Science. 46:614-621.

Bernardo, R., and Yu, J. 2007. Prospects for genome wide selection for quantitative traits in maize. Crop Science. 47: 10821090.

Chang, M.T., Coe, E.H. Jr. 2009. Doubled haploids. In: Kriz AL, Larkins BA (eds) Molecular genetic approaches to maize improvement. Biotechnology in agriculture and forestry. Vol 63 . Springer, Berlin.

Chen, Z., Wang, B., Dong, X., Liu, H., Ren, L., Chen, J., Hauck, A., Song, W., and Lai, J. 2014. An ultra-high density bin-map for rapid QTL mapping for tassel and ear architecture in a large F2 maize population. BMC Genomics.15, 433.

Crosbie, T.M., Eathington, S.R. and Johnson, G.R. 2006. Plant breeding: past, present, and future. In: Lamkey KR, Lee M, eds. Plant breeding: the Arnel R. Hallauer international symposium. Ames, IA: Blackwell Publishing.

Eathington, S. 2005. Practical applications of molecular technology in the development of commercial maize hybrids. In: Proceedings of the 60th Annual Corn and Sorghum Seed Research Conferences. Washington, DC: American Seed Trade Association.

Forster, B.P., and Thomas, W.T.B. 2005. Doubled haploids in genetics and plant breeding. Plant Breed Rev. 25:57-88.

Frisch, M., Bohn, M., and Melchinger, A.E. 1999. Minimum sample size and optimal positioning of flanking markers in marker-assisted backcrossing for transfer of a target gene. Crop Science. 39: 967975.

Garg, A., Prasanna, B.M., and Sharma, R.C. 2009. Genetic analysis and mapping of QTLs for resistance to banded leaf and sheath blight (Rhizoctonia solani f.sp. sasakii) in maize. In: Proceedings of 10th Asian regional maize workshop (October 20-23, 2008, Makassar, Indonesia). CIMMYT, Mexico DF (in press).

George, M.L.C, Prasanna, B.M., and Rathore, R.S. 2003. Identification of QTLs conferring resistance to downy mildews of maize in Asia. Theor. Appl. Genet. 107: 544-551.

Gerpacio, R.V., and Pingali, P.L. 2007. Tropical and subtropical maize in Asia: production systems, constraints, and research priorities. CIMMYT, Mexico DF.

Gupta, H.S., Agrawal, P.K., and Mahajan, V. 2009. Quality protein maize for nutritional security: rapid development of short duration hybrids through molecular marker assisted breeding. Curr Sci. 96: 230-237. 
Gupta, P.K., Rustgi, S., Kulwal, P.L. 2005. Linkage disequilibrium and association studies in plants: Present status and future prospects. Plant Molecular Biology. 57:461-485.

Hao, Z., Li, X., and Xie, C. 2008. Two consensus quantitative trait loci clusters controlling anthesis-silking interval, ear setting and grain yield might be related with drought tolerance in maize. Ann. Appl. Biol. 153: 73- 83.

Holland, J. B. 2004. Implementation of molecular markers for quantitative traits in breeding programs-challenges and opportunities. In: Proc. 4th Int. Crop Sci. Congress. Brisbane, Australia, 26 September-1 October.

Hospital, F. 2005. Selection in backcross programmes. Phil. Trans. R. Soc. B. 360: 1503-1511.

Hospital, F., and Charcosset, A. 1997. Markerassisted introgression of quantitative trait loci. Genetics. 147: 1469-1485.

Jhansi, R.P., Satyanarayana, P.V., Chamundeswari, N., and Girija Rani, M. 2014. A review on Marker Assisted Selection in crop improvement. Internation Journal of Applied Biology and Phramaceutical Technology. 5:271281

Jiang, G.L., Shi, J., and Ward, R.W. 2007a. QTL analysis of resistance to Fusarium head blight in the novel wheat germplasm CJ 9306. I. Resistance to fungal spread. Theoretical and Applied Genetics.116:3-13.

Li, H., Ye, G., Wang, J. 2007. A modified algorithm for the improvement of composite interval mapping. Genetics. 175, 361-374.

Liu, C., Zhou, Q., Dong, L., Wang, H., Liu, F., Weng, J., Li, X., Xie, C. 2016b. Genetic architecture of the maize kernel row number revealed by combining QTL mapping using a high-density genetic map and bulked segregant RNA sequencing. BMC Genomics, 17, 915.

Lu, Y., Zhang, S., Shah, T., Xie, C., Hao, Z., Li, X., Farkhari, M., Ribaut, J.M., Cao, M.,
Rong, T., Xu, Y. 2010. Joint linkagelinkage disequilibrium mapping is a powerful approach to detecting quantitative trait loci underlying drought tolerance in maize. In: Proceedings of the National Academy of Sciences of the United States of America.107, 1958519590.

Messmer, R., Francheboud, Y., Banziger, M., Vargas, M., Stamp, P., and Ribaut, J.M. 2009.Drought stress and tropical maize: QTL-by environment interactions and stability of QTLs across environments for yield.

Meuwissen, T. 2007. Genomic selection: marker assisted selection on a genome wide scale. J. Anim. Breed. Genet. 124: 321-322.

Meuwissen, T.H.E., Hayes, B.J., and Goddard, M.E. 2001. Prediction of total genetic value using genome wide dense marker maps. Genetics. 157: 1819-1829.

Morris, M., Dreher, K., Ribaut, J.M., and Khairallah, M. 2003. Money matters (II): costs of maize inbred line conversion schemes at CIMMYT using conventional and marker assisted selection. Mol Breed. 11:235-247

Nair, S.K., Prasanna, B.M., and Garg, A. 2005. Identification and validation of QTLs conferring resistance to sorghum downy mildew (Peronosclerospora sorghi) and Rajasthan downy mildew $(P$. heteropogoni) in maize. Theor. Appl. Genet.110:1384-1392.

Nakaya, A., and Isobe, S.N. 2012. Will genomic selection be a practical method for plant breeding? Annals of Botany. DOI:10.1093/aob/mcs109.

Pingali, P.L., and Pandey, S. 2001. Meeting world maize needs: technological opportunities and priorities for the public sector. In: Pingali PL (ed.) CIMMYT 1999/2000 world maize facts and trends. CIMMYT, Mexico DF, pp 1-24.

Prasanna, B.M., Beiki, A.H., Sekhar, J.C., Srinivas, A., and Ribaut, J.M. 2009a. Mapping QTLs for component traits influencing drought stress tolerance of 
maize in India. J. Plant Biochem. Biotech. 18:151-160.

Prasanna, B.M., Mahatman, K.H., Rajan, A., Singh, O.N., Kaur, B., Zaidi, P.H., Azrai, M., and Pixley, K.N. 2009b, 2010a. Molecular marker-assisted pyramiding of genes conferring resistance to Turcicum leaf blight and Polysora rust in maize inbred lines in India. In: Proceedings of 10th Asian regional maize workshop (October 20-23, 2008, Makassar, Indonesia). CIMMYT, Mexico DF.

Prasanna, B.M., Vasal, S.K., Kassahun, B., and Singh, N.N. 2001. Quality protein maize. Curr Sci 81:1308-1319.

Ribaut, J. M., Vicente, M. C., and Delannay, X. 2010. Molecular breeding in developing countries: challenges and perspectives. Current Opinion in Plant Biology.13: 16, 213-218.

Ribaut, J.M., and Hoisington, D. 1998. Markerassisted selection: new tools and strategies. Trends Plant Science.3: 236239.

Ribaut, J.M., and Ragot, M. 2007. Markerassisted selection to improve drought adaptation in maize: The backcross approach, perspectives, limitations, and alternatives. J. Exp. Bot. 58: 351-360.

Salina, E., Dobrovolskaya, O., Efremova, T., Leonova, I., and Roder, M.S. 2003. Microsatellite monitoring of recombination around the Vrn-B1 locus of wheat during early backcross breeding. Plant Breed. 122: 116-119.

Septiningsih, E.M., Pamplona, A.M., Sanchez, D.L., Neeraja, C.N., Vergara, G.V., Heuer, S., Ismail, A.M., and Mackill, D.J. 2009. Development of submergencetolerant rice cultivars: The Sub1 locus and beyond. Annals of Botany. 103:151160.

Shiferaw, B., Prasanna, B., Hellin, J., and Banziger, M. 2011. Crops that feed the world 6. Past successes and future challenges to the role played by maize in global food security. Food Security. 3:307-327.

Steele, K.A., Price, A.H., Sashidhar, H.E., and Witcombe, J.R. 2006. Marker-assisted selection to introgress rice QTLs controlling root traits into an Indian upland rice variety. Theoretical and Applied Genetics. 112:208-221.

Varshney, R.K., and Tuberosa, R. 2007. Genomics-Assisted Crop Improvement: Genomics Approaches and Platforms. The Netherlands: Springer Vol. I.

Xiao, Y.N., Li, X.H., and George, M.L. 2005. Quantitative trait loci analysis of drought tolerance and yield in maize in China. Plant Mol. Biol. Reporter. 23:155-165.

\section{How to cite this article:}

Sandeep Bagri, Rajat, Sahil, Harmeet Singh Janeja. 2020. Molecular Breeding in Maize Improvement. Int.J.Curr.Microbiol.App.Sci. 9(12): 722-729. doi: https://doi.org/10.20546/ijcmas.2020.912.087 